\title{
Viral infections and the development of asthma in children
}

\author{
Sejal Saglani
}

Abstract: Viral aetiology, host susceptibility (in particular allergic predisposition and sensitization), and illness severity, timing and frequency all appear to contribute as synergistic factors to the risk of developing asthma. Experimental models have shown both innate and adaptive immune responses contribute to this risk with lung inflammatory cells showing marked differences in phenotype and function in young compared with older animals, and these differences are further enhanced following virus infection. Findings to date strongly suggest that the impact of infant and preschool viral infections on the maturing immune system and developing lung that subsequently result in an asthma phenotype occur during a critical susceptibility period, and in a genetically susceptible host. There are currently no therapeutic strategies that allow primary or secondary prevention of asthma following early life viral respiratory infections in high-risk children, thus a focus on understanding the mechanisms of progression from viral wheezing in infants and preschool children to asthma development are urgently needed. This review summarizes the data reporting the role of the two most common viruses, that is, respiratory syncytial virus and human rhinovirus, that result in asthma development, comparing risk factors for disease progression, and providing insight into strategies that might be adopted to prevent asthma development.

Keywords: asthma, preschool wheeze, respiratory syncytial virus, rhinovirus, virus

\section{Introduction}

All children in early life are infected with a respiratory virus, and more than half experience associated lower respiratory tract (LRT) disease, which is clinically manifest as wheezing or other signs of respiratory distress, before school age [Jartti et al. 2004; Wright et al. 1989]. Using molecular diagnostics, a viral pathogen can be identified in the majority of wheezing episodes that occur in the first 5 years of life [Jackson et al. 2008]. The most common viruses associated with these early onset wheezing episodes are respiratory syncytial virus (RSV), human rhinovirus (HRV), and human metapneumovirus [Calvo et al. 2007; Fujitsuka et al. 2011; GarciaGarcia et al. 2007; Jartti et al. 2004].

\section{Definitions and terminology}

Acute viral infections in infancy (first year of life) may manifest in several ways including upper airway symptoms alone (coryza, runny nose) or with lower respiratory symptoms including tachypnoea, respiratory distress and wheezing (also termed virus-associated wheezing or acute bronchiolitis). After the acute infection, infants are at increased risk of wheezing episodes with subsequent virus infections (postviral wheeze, virus-associated wheeze or episodic wheeze). Some infants and preschool children (aged 1-5 years) may then have a change in the pattern of wheezing, such that they wheeze both with virus infections and in between (persistent wheeze or multiple-trigger wheeze). Asthma is not usually diagnosed until school age ( $>5$ years), and is characterized by allergic sensitization, variable airflow obstruction and wheezing.

\section{Prevalence of virus-associated wheezing illnesses in infancy and preschool years}

Wheezing illnesses in young children are almost exclusively (up to 95\%) associated with respiratory viral infections [Allander et al. 2007; Lemanske et al. 2005]. RSV dominates in bronchiolitis during the winter months. The overall prevalence of RSV bronchiolitis depends on yearly epidemics, but it may be up to $80 \%$ in infants aged less than 3 months and rapidly
Ther Adv Infect Dis (2013) 1(4) 139-150 DOI: 10.1177/ 2049936113497202

(C) The Author(s), 2013. Reprints and permissions: http://www.sagepub.co.uk/ journalsPermissions.nav

Correspondence to: Sejal Saglani, BSc, MB ChB, MD

Clinical Senior Lecturer, Respiratory Paediatrics, 374 Sir Alexander Fleming Building, Imperial College, London SW7 2AZ, UK s.saglani@imperial.ac.uk 
decreases thereafter [Jartti et al. 2009; Rakes et al. 1999].

In older, preschool children with wheeze, the common cold virus, HRV, is most often detected. The transition in dominance between HRV and RSV is around 12 months of age in hospitalized wheezing children [Jartti et al. 2009]. The prevalence of HRV-associated wheezing increases with age. Approximately $20-40 \%$ of infants (under 1 year old) with bronchiolitis have HRV infection, increasing to about $50 \%$ of hospitalized wheezing children by 3 years, and $50-85 \%$ in older wheezing children or children with an asthma exacerbation [Escobar et al. 2010; Johnston et al. 1995].

\section{Clinical infant and preschool wheeze pheno- types and asthma development}

The onset of wheezing associated with lower respiratory virus infections in infants and preschool children is well recognized. Birth cohort studies have described broad clinical phenotypes of wheezing based on symptom pattern. The first of these cohorts was the Tucson Children's Respiratory Study (TCRS) carried out in Tucson, AZ, USA, which described four main clinical phenotypes determined by wheeze pattern and age [Martinez et al. 1995]: (a) children with no LRT wheezing illness in the first 3 years (never wheezers); (b) at least one LRT wheezing illness in the first 3 years, but none between 3 years and 6 years (transient early wheezers); (c) no LRT wheezing in the first 3 years, but wheeze present at age 6 years (late-onset wheezers); (d) at least one wheezing LRT illness in the first 3 years and wheeze present at age 6 years (persistent wheezers) [Taussig et al. 2003].

More recently, these phenotypes have been validated, and indeed enriched by other cohorts. In the UK the Avon Longitudinal Study of Parents and Children (ALSPAC) cohort has described further refinements to the phenotypes described in the TCRS. By separating the TCRS 'transient early' wheeze into 'early' (wheeze only in the first year) and 'transient' wheeze, differing associations were seen. Children that only wheezed in the first year had no reduction in lung function or increased risk of atopy, and were similar to the never wheezers. However, the transient wheezers that had wheezed for the first 3 years, but were no longer symptomatic at age 6 years still had abnormal lung function at 6 years despite an absence of symptoms [Collins et al. 2013; Henderson et al. 2008].
Subsequently, the phenotypes described in the ALSPAC study were compared with those in the Prevention and Incidence of Asthma and Mite Allergy (PIAMA) study [Savenije et al. 2011]. Phenotypes identified in the PIAMA study had wheezing patterns that were similar to those reported in ALSPAC. Associations with asthma, atopy and lung function were remarkably similar in the two cohorts [Savenije et al. 2011].

Associations between lower respiratory wheezing illnesses caused by viral infections in early life and subsequent increased risk of asthma development have since been confirmed, specifically in relation to RSV [Sigurs et al. 2010], and HRV [Jackson et al. 2012]. Importantly, associations have been shown between early virus infections and the onset of airway dysfunction [Dakhama et al. 2005], with relationships between early wheeze phenotypes and reduced lung function being maintained until adulthood [Sherrill et al. 2011; Stern et al. 2008].

The role of virus infections in the first 3 years of life and subsequent development of asthma Depending on the study design and length of follow up, approximately one-third of infants who wheeze in the first 3 years of life continue to wheeze after the age of 3 years [KotaniemiSyrjanen et al. 2002; Martinez et al. 1995; Matricardi et al. 2008]. Even a mild wheezing episode during infancy may be a significant risk factor for persistent wheezing and asthma later in life. Prospective studies have shown that about $30 \%$ of infants who wheeze in early life continue to report wheezing symptoms in the preschool years. A population-based study, which used a healthcare specialist-confirmed diagnosis of bronchiolitis, showed that $16 \%$ of infants aged under 1 year with an outpatient visit for bronchiolitis had frequent wheezing symptoms or asthma at age 4-5.5 years [Carroll et al. 2009]. After hospital admission for wheezing in infancy $18-53 \%$ of preschool children experience frequent symptoms or asthma, and the prevalence of school-age asthma, at 7.6-9.5 years of age, has been 15-40\% [Henderson et al. 2005; Korppi et al. 1994; Kotaniemi-Syrjanen et al. 2005; Sigurs et al. 2000; Valkonen et al. 2009].

\section{Virus type and progression to asthma}

A key underlying issue is the relative strength of the associations between different respiratory viruses and early asthma pathogenesis. Earlier studies emphasized the key role of RSV 
[Sigurs et al. 2010; Wu and Hartert, 2011], however, recent attention has shifted toward the importance of rhinovirus infection in infancy [Jartti and Gern, 2011; Jartti and Korppi, 2011], and subsequent asthma [Koponen et al. 2012; Kotaniemi-Syrjanen et al. 2003]. However, RSV remains a major pathogen in infants, and the relative roles of RSV and rhinoviruses in driving asthma beyond childhood are still not completely understood [Bacharier et al. 2012; Jackson et al. 2012; Ruotsalainen et al. 2013]. As these seem the two predominant virus types that are reported to cause persistent wheezing and asthma, studies defining their role in asthma development will be considered in more detail.

\section{RSV infection in infancy and preschool years and asthma development}

Almost all children are seropositive for RSV in the first 2 years of life, yet the clinical manifestations of infection are hugely variable. Most children are either asymptomatic or have only mild upper respiratory symptoms, but a small number develop severe lower respiratory symptoms during the acute illness with respiratory distress, tachypnoea and wheeze, and require hospitalization. A big clinical challenge that results after RSV infection in infants and preschool children relates to its long-term sequelae, which include recurrent wheezing and the development of asthma. Long-term prospective case-control and cohort studies have linked RSV bronchiolitis to the development of wheeze and asthma in childhood. Studies by Sigurs and colleagues have demonstrated a 7.2-fold increased risk of asthma up to 18 years after LRT infection with RSV resulting in bronchiolitis [Sigurs et al. 2010]. However, this cohort was relatively small $(n=47)$, and all had a severe initial episode that required hospitalization, and the high incidence of future asthma in the group with RSV-positive bronchiolitis in infancy may also be related to the age of the infants, all of whom were under 1 year, with $90 \%$ under 6 months. Overall, these data have highlighted the importance of the severity of the initial episode in contributing to the development of future asthma. Epidemiological studies suggest that children receiving hospitalbased care for acute bronchiolitis experience a 2.8 -fold increased risk of asthma by $4.5-5.5$ years of age [Carroll et al. 2009]. Importantly, the Sigurs and colleagues' cohort has also demonstrated an association between severe RSV infection in infancy and subsequent allergic sensitization at ages 3-18 years [Sigurs et al. 2000, 2010]. However, the impact of early RSV infection on subsequent asthma remains controversial since other cohorts including the TCRS have shown that although early RSV infection was associated with wheezing until age 11 years, subsequently, by 13 years, there was no added effect [Stein et al. 1999]. However, children in the TCRS cohort did not all have severe disease, and this likely affects long-term outcomes.

The RSV Bronchiolitis in Early Life study is a prospective cohort of infants hospitalized for RSV bronchiolitis and focuses on identifying predictors of post-RSV asthma [Bacharier et al. 2012]. Of the 206 children enrolled with severe RSV bronchiolitis during the first year of life, $48 \%$ had received a physician's diagnosis of asthma by their seventh birthday. Risk factors for an asthma diagnosis could be identified in the first year of life, with maternal asthma and high levels of dog allergen exposure being associated with an increased risk of asthma, whereas White ethnicity and day-care attendance were associated with decreased risk of asthma. Allergic sensitization at age 3 years was also associated with an increased risk of physician's diagnosis of asthma [Bacharier et al. 2012].

While an association between severe RSV infection during infancy and the development of childhood asthma is documented, causation has been long debated: does RSV infection cause a long-term change in the host, which increases the subsequent risk of asthma? Or is RSV bronchiolitis simply an early marker of a predisposition for asthma? A few recent studies have aimed to address this question. The relationship between infant age at their first winter viral peak following birth and subsequent asthma risk during the fifth and sixth year of life has been investigated to address this question. Infants who were 4 months old at the peak of winter viral season were more likely to develop both bronchiolitis and childhood asthma [Wu et al. 2008]. This suggests a causal role of early RSV infection on asthma development. A possible mechanism is that infants under 4 months of age have lost most maternal antibodies, and their immunoglobulin G level is at its nadir [Ochola et al. 2009; Stensballe et al. 2009a]. In addition, RSV infection during this period of infancy, when both the immune system and developing lung are immature, affects immune regulation and lung development resulting in chronic airway 
dysfunction [Gern et al. 2005]. Three additional studies have been carried out to assess causality between RSV infection in infancy and childhood asthma using a population-based study among twins in Denmark [Poorisrisak et al. 2010; Stensballe et al. 2009b; Thomsen et al. 2009]. The first study fitted models of genetic variance components and direction of causation to over 8000 twin pairs [Thomsen et al. 2009]. When this was done, the hypothesis that asthma causes RSV hospitalization was feasible, whilst RSV hospitalization causes asthma was rejected. A second twin study showed the effect of RSV hospitalization on asthma was only for a short time (up to 2 months after hospitalization), and subsequently the increased risk of wheezing was lost by 1 year of age [Stensballe et al. 2009b]. Lastly, a study of 37 monozygotic twins, discordant for severe RSV bronchiolitis in infancy, indicated no effect of severity of RSV infection on asthma development [Poorisrisak et al. 2010]. All of the reported twin studies therefore have not supported a causal link between early RSV infection and asthma, but suggest an inherent susceptibility to asthma determines RSV infection. However, the twin studies used data from the patient registry, which does not contain information about outpatient visits. Therefore, any conclusion about causality suffers from the misclassification of twins not hospitalized with RSV infection to an uninfected group. In addition, symptoms were only assessed until 1 year of age in two of the three studies, and 3 years of age in the third, but asthma diagnosis can only reliably be made at school age. The children may therefore have been wrongly labelled as asthmatic when they may only have had transient early wheeze. Assessment at school age may have influenced the results.

There is little doubt from prospective cohorts that RSV infection in infancy, especially when associated with symptoms of LRT disease (tachypnoea, respiratory distress and wheeze), results in an increased risk of subsequent wheezing. However, the data at present do not allow any conclusions to be drawn about causal direction between asthma and RSV infection in infancy and preschool years. Overall, it appears that the wheezing tends to resolve by school age in those with mild to moderate symptoms, whilst the risk of symptom persistence and asthma development is increased in those with an episode severe enough to result in hospitalization, and under 6 months of age, and with early allergic sensitization.

A possible way of addressing causation, other than longitudinal cohort studies, is to look mechanistically in vivo in animal models. These animal studies have shown initial neonatal RSV infection has a long-term impact on immune responses to subsequent viral infection in adulthood [Culley et al. 2002]. They have also shown neonatal RSV infection results in immunomodulation with an altered T-regulatory cell phenotype [Krishnamoorthy et al. 2012], such that responses to subsequent infection or allergen exposure are biased towards a $\mathrm{T}$ helper 2 (Th2)-allergic phenotype. Neonatal priming by RSV infection increased inflammatory cell recruitment (including Th2 cells and eosinophils) during re-infection, whereas delayed priming led to enhanced interferon (IFN) $-\gamma$ production and less severe disease during re-infection. Thus, LRT infections during an active period of immune and lung development could adversely affect these processes and result in airway remodelling or interfere with the generation of new alveoli [Gern et al. 2005].

\section{HRV infection in infancy and preschool age and asthma development}

Until recently, RSV infection in infancy was thought be the predominant virus that influenced the development of asthma by school age. However, it is becoming increasingly apparent that HRVs are likely to be as important in influencing progression to asthma. HRVs are the most frequent cause of the common cold and have traditionally been considered to be isolated to the upper airway. However, HRV invades and replicates in the lower airway following inoculation of the upper airway [Papadopoulos et al. 2000]. An advantage in more recent studies is the development of improved molecular diagnostics that have allowed the identification of HRVs as pathogens frequently causing wheezing illnesses in infants and young children. Importantly, HRV infection, in a similar manner to RSV infection, leads to a broad spectrum of illness severity. Some infants and children infected with HRV may be asymptomatic, whereas others may have an illness severe enough to lead to hospitalization. However, the susceptibility of HRV bronchiolitis seems to be closely linked to allergic predisposition, since the prevalence of HRV bronchiolitis has been up to $50-80 \%$ during the first year of life in recurrently 
ill infants of atopic families [Jartti et al. 2008]. This suggests that host factors play an important role in the severity of illnesses caused by HRV. Identifying the relative contribution of host and virus-related factors toward asthma development are critical ongoing areas of investigation that may lead to new therapeutic and prevention strategies for preschool wheezing illnesses and asthma.

Seminal data that revealed the importance of early HRV infection and asthma development came from the Childhood Origins of Asthma (COAST) study. A key point, however, was that this cohort only included children with at least one atopic parent, and therefore were considered 'high risk', with a prior susceptibility to allergic disease. This was in contrast to all previous cohorts that had recruited either nonselectively, or had recruited based on severity of the viral infection. COAST identified HRV wheezing illnesses during the first year of life as significant predictors of wheezing in the third year of life [Lemanske et al. 2005], and asthma at 6 years [Jackson et al. 2008]. Children with HRV wheezing illnesses and aeroallergen sensitization during infancy had the greatest risk of asthma at school age. Independent confirmation of these findings was reported in a further, very similar, high-risk cohort in Australia. HRV wheezing illnesses during the first year of life were associated with increased asthma risk at the age of 5 years, although this finding was restricted to children who developed aeroallergen sensitization by the age of 2 years [Kusel et al. 2007]. Thus, two separate and unrelated birth cohorts have identified HRV wheezing illnesses during infancy and early aeroallergen sensitization as risk factors for childhood asthma development.

It appears that the age at which HRV wheezing illnesses occur has significant prognostic value with regard to subsequent risk of asthma. Children who wheezed with HRV during the first year of life had an approximately three-fold risk of having asthma at the age of 6 years. HRV wheezing in the second year was associated with a higher asthma risk, and wheezing with HRV infection during the third year of life was associated with a very high risk of developing asthma at school age, with an odds ratio of 32 [Jackson et al. 2008].

More recently, the causal relationship between allergic sensitization and early HRV infection to asthma development has been investigated in the COAST cohort. Prospective characterization of the cohort demonstrated that allergic sensitization preceded HRV wheezing, but HRV wheezing did not result in an increased risk of allergic sensitization [Jackson et al. 2012]. This sequential relationship supports a causal role for allergic sensitization in this developmental pathway. Therefore, treatments aimed at preventing allergic sensitization may modify the long-term consequences of virus-induced wheezing. The importance of early allergic sensitization in asthma development after HRV infection highlights why these findings were only seen in high-risk children studied in this cohort, with parental atopy and thus host susceptibility.

\section{Direct comparisons of HRV and RSV}

The Tennessee Children's Respiratory Initiative [Carroll et al. 2012] aimed to determine whether maternal asthma was associated with a higher risk of infant respiratory tract infection with HRV compared with RSV, and whether maternal asthma was associated with increased infection severity. They reported that having a mother with atopic asthma significantly increased the risk of the infant experiencing HRV infection compared with RSV infection. Interestingly, maternal asthma increased the severity of infant HRV infection but not that of RSV infection. These findings suggest that, compared with infants with RSV infection, infants with HRV infections are more likely to have an atopic predisposition reflected by positive family history; it might be that this atopic predisposition modulates the increased risk for asthma among children who wheeze with HRV [Carroll et al. 2012]. The risk factors that have been identified as important in determining progression to asthma in studies that have addressed RSV and rhinoviruses are summarized in Table 1.

\section{Mechanisms underlying early virus infection and asthma development}

It is accepted that preschool wheezing disorders consist of several distinct disease entities, but there is no agreement on underlying mechanisms. As discussed earlier, commonly used phenotypic classifications are based on clinical or epidemiological criteria, but there has been little work focusing on causal mechanisms.

\section{Early allergic sensitization}

Interestingly, reduced IFN- $\gamma$ responses in infancy are observed in children with atopic features, 
Table 1. Risk factors for asthma development following early viral respiratory illnesses: comparison of rhinovirus and respiratory syncytial virus.

\begin{tabular}{|c|c|c|}
\hline & Rhinovirus & Respiratory syncytial virus \\
\hline Age & $\begin{array}{l}\text { Increasing risk from first to third } \\
\text { year of life }\end{array}$ & $\begin{array}{c}\text { Increased risk in first year of life, } \\
\text { especially under } 6 \text { months }\end{array}$ \\
\hline Illness severity & $\begin{array}{l}\text { No obvious impact on risk of } \\
\text { asthma }\end{array}$ & $\begin{array}{l}\text { More severe disease increased } \\
\text { the risk of asthma }\end{array}$ \\
\hline Parental atopy & Increased risk of asthma & $\begin{array}{l}\text { Increased asthma risk with } \\
\text { maternal atopy }\end{array}$ \\
\hline $\begin{array}{l}\text { Early allergic sensitization and } \\
\text { prevalence of atopy (eczema } \\
\text { or hayfever) }\end{array}$ & $\begin{array}{l}\text { Predisposition to rhinovirus } \\
\text { infection and subsequent } \\
\text { asthma }\end{array}$ & $\begin{array}{l}\text { Associated with increased risk of } \\
\text { asthma development }\end{array}$ \\
\hline $\begin{array}{l}\text { Immune responses to } \\
\text { re-infection }\end{array}$ & Unknown & $\begin{array}{l}\text { Early infection in infancy skews } \\
\text { immune responses towards } \\
\text { Th2 phenotype with subse- } \\
\text { quent infection later in life }\end{array}$ \\
\hline Lung-function deficit & $\begin{array}{l}\text { Early deficit present at birth, or } \\
\text { following infections in the first } \\
3 \text { years of life, may increase } \\
\text { risk of asthma }\end{array}$ & $\begin{array}{l}\text { Early deficit present at birth, or } \\
\text { resulting from first severe } \\
\text { infection, leads to increased } \\
\text { risk of asthma }\end{array}$ \\
\hline
\end{tabular}

which could help to explain why atopy is a risk factor for virus-induced wheezing and the progression to asthma. Several studies have linked HRV-induced wheezing in infancy to allergic sensitization, nasal and systemic eosinophilia, and clinically diagnosed atopic eczema [Korppi et al. 2004; Kusel et al. 2007]. The presence of respiratory allergen-specific immunoglobulin $\mathrm{E}$ (IgE) and high total $\operatorname{IgE}$ is a risk factor for viral wheeze in children presenting for emergency care [Bousquet et al. 2008].

\section{Immune responses and RSV infection}

\section{Animal studies}

The limitations in establishing causality of virus infection and asthma in humans has resulted in many viruses being used to develop animal models of human disease, with studies in mice and use of RSV infection predominating [Han et al. 2011]. Most of these murine studies utilized intranasal inoculation of human RSV with viral replication peaking 3-4 days after infection. In mice, RSV can induce the production of a wide variety of pro-inflammatory cytokines that are Th1 (IFN-g), Th2 (interleukin [IL]-4, IL-5, IL13) and regulatory (IL-10), as well as pro-inflammatory lipid mediators [Fullmer et al. 2005; Han et al. 2010]. RSV infection can induce airway hyperresponsiveness (AHR) to inhaled methacholine and neutrophilic and eosinophilic inflammation [Han et al. 2011]. Epithelial cell damage and inflammation are also involved in RSVinduced AHR in mice [Dakhama et al. 2005].
However, a big limitation of numerous experimental studies to date is the use of adult mice, thus failing to account for immune maturation and lung development. One recent study has introduced RSV infection in neonatal mice and shown evidence of neutrophilia with increased mucous production, but has not shown altered lung function, or assessed long-term sequelae [Empey et al. 2012]. In animal studies, RSV primary infection during the neonatal period predisposes $\mathrm{BALB} / \mathrm{c}$ mice to a more severe disease upon re-infection in adulthood compared with mice with delayed RSV primary infection [Culley et al. 2002; Dakhama et al. 2005].

\section{Human studies}

Infant immune modulation is a proposed mechanism through which RSV may cause asthma. It has been shown that RSV infection in infancy may alter subsequent Th1/Th2 immune responses, enhance Th2 sensitization to aeroallergens, and thus induce the development of an asthmatic phenotype [Macaubas et al. 2003; Martinez et al. 1998]. Alteration of Th1 and Th2 cytokine levels have been linked to severe RSV bronchiolitis. Severe RSV disease is thought to be associated with Th2 polarization of the lung immune response and may then 'sensitize' the host's allergic responses to other molecules [Stephens et al. 2002].

IFN- $\gamma$ (a Th1 cytokine) expression in peripheral blood mononuclear cells (PBMCs) was reduced among infants with more severe RSV 
bronchiolitis compared with those with mild disease [Aberle et al. 1999]. In addition, hospitalized infants were reported to have diminished IFN- $\gamma$ production from PBMCs during and in the months after RSV bronchiolitis, but only in those children who later developed asthma [Renzi et al. 1999]. However, it is unclear if the PBMCs reflect the local pulmonary response that occurs after acute RSV infection. In infants, young age at first RSV infection has been associated with Th2 responses [Kristjansson et al. 2005]. This was demonstrated by higher levels of IL-4 in RSV-positive infants younger than 3 months of age compared with those older than 3 months of age. This may suggest that for RSV infection, the earlier the first infection, the more skewed the immune response may be.

In addition, there is now evidence that different RSV strains impact the immune system and airway function differently in primary human bronchial epithelial cells [Stokes et al. 2011]. Thus, the interplay between age at initial infection, genetic susceptibility polymorphisms and virus strain will likely dictate the outcome of respiratory virus infection and airway disease.

\section{Immune responses and $\mathbf{R V}$ infection}

Two immunological factors, IFN responses and atopy, have been associated with susceptibility to HRV bronchiolitis in multiple studies. These findings support the hypothesis that susceptibility to HRV bronchiolitis is likely to be an early manifestation of biased immune responses, which could be linked to both decreased viral defence and atopic airway inflammation.

\section{Animal studies}

Mechanisms of rhinovirus infection are difficult to study in mouse models because of difficulties relating to viral replication and lung infection with rhinovirus in mice. However, a recent neonatal model of intranasal rhinovirus (RV1B) infection on day 7 of life has been reported [Schneider et al. 2012]. Although viral RNA persisted in the lungs for up to 7 days postinfection, no evidence of active viral replication or lung infection is provided. At 28 days after neonatal rhinovirus infection (when the mice were young adults) there was evidence of sustained altered airway function (increased airway hyperresponsiveness) and altered pulmonary immune responses demonstrated by percentages of CD4-positive $\mathrm{T}$ cells expressing IFN- $\gamma$ and cells expressing IL-13. In contrast, adult mice infected with RV1B showed no change in IL-13 expression, mucus production or airway hyperresponsiveness 28 days after infection [Schneider et al. 2012].

Collectively, these studies suggest that HRV infection that results in wheezing in children could serve as a tool for early identification of asthma-prone children. The findings to date provide the rationale for future studies to incorporate early HRV wheezing episodes into an improved clinical asthma risk index.

\section{Gaps in knowledge and future research}

The dilemma of whether viral bronchiolitis early in life is the cause of future asthma or a marker for susceptibility for asthma is not yet resolved. It is likely that both of these pathways are relevant, and there may be differential effects based on the child's atopic predisposition and the specific virus.

There remains a need therefore to understand the mechanisms by which infant RSV and HRV infection impacts the development of asthma, and to understand and identify the critical time periods during which RSV infection confers the greatest impact on asthma risk. While RSV infection is ubiquitous in young children, not all infants who develop bronchiolitis become asthmatic. Thus, understanding how RSV infection interacts with genetic and other environmental risk factors will be important in asthma prevention, as well as selecting high-risk populations for primary-prevention interventions. It seems apparent that the use of age-appropriate experimental animal models to determine mechanisms is a critical requirement for future studies, which should have the goal of identifying novel therapeutic and prevention strategies for both early childhood wheezing and asthma.

\section{Potential for primary- and secondary-disease prevention}

In general, wheezing disorders in preschool children do not respond well to anti-inflammatory therapies used for asthma, and utilize a disproportionate number of healthcare resources when compared with older children and adults with asthma [Akinbami and Schoendorf, 2002]. In addition, conventional therapies, including inhaled steroids, do not alter the natural history of the disease [Bisgaard et al. 2006; Guilbert et al. 2006]. Given that significant alterations occur in immune responses, lung function [Lowe et al. 2002, 2005], and airway structure 
[O'Reilly et al. 2013; Saglani et al. 2005, 2007], between infancy and the preschool years, in children that develop asthma, the ultimate goal is to identify high-risk subjects between infancy to preschool age and use measures to reduce atopic and viral-associated inflammation early enough to block disease initiation. The clinical preschool wheeze phenotype shows a high degree of plasticity at these early ages (between 1 year and 3 years) but becomes progressively less reversible thereafter, marking this period as a potentially ideal therapeutic window for longterm disease modification. The growing evidence indicating a central role for early LRT infections, including bacterial infections [Bisgaard et al. 2010], in the development of persistent asthma in atopic children has served to elevate respiratory viral infections towards the head of the list of prospective therapeutic targets for primary prevention of asthma. The dilemma faced by researchers is the current lack of antiviral agents that are approved for use in children. The anti-RSV monoclonal antibody palivizumab is available as a potential primarypreventive therapy. However, as it is expensive it is currently only licensed for use in children with significant comorbidities who are at high risk of developing severe disease. A recent Cochrane review has concluded that in this high-risk group the risk of hospitalization with severe disease is reduced [Andabaka et al. 2013], however, there are no long-term follow-up studies to date that have determined the impact on asthma development.

One area of particular interest concerns attempts to boost endogenous anti-inflammatory mechanisms in the lung by oral administration of immunomodifying agents such as live probiotics to reduce the intensity and duration of inflammatory symptoms associated with respiratory infections [de Vrese et al. 2006]. Interest in the use of probiotics is increasing, and the search for formulations that may increase clinical effect, which is currently difficult to elicit, is being investigated. Related possibilities with similar principles involve the use of oral extracts derived from bacteria as opposed to live organisms. One such example is the bacterial-derived OM-85, which has been used in Europe to treat immunocompromised adults and children susceptible to repeated LRT infections. A recent study demonstrated a 38\% reduction in the rate of wheezing attacks, with a 2-day shorter duration of symptoms in preschool children with recurrent wheezing [Razi et al. 2010]. Another potential approach to immunomodulation includes the use of vitamin D supplementation. Protection against respiratory infections in children has recently been suggested as a mechanism to explain the effects of this agent [Camargo et al. 2011]. A small trial has shown that vitamin D supplementation in atopic asthmatic school children has potential for the prevention of virusassociated asthma exacerbations [Majak et al. 2011]. The underlying mechanism remains unknown, but a link between vitamin $\mathrm{D}$ levels and T-regulatory cells in infants has been reported [Chi et al. 2011], and suggests that these immunomodulatory associations warrant further investigation in infants and preschool children with virus-associated wheezing disorders.

\section{Summary}

It is apparent that infants and preschool children that wheeze with viral infections may have persistent symptoms and progress to develop asthma by school age. The data so far show severe infections, as well as early allergic sensitization are important risk factors for progression of virusrelated wheezing to asthma. RSV and HRV are the most common viruses that appear to be associated with asthma development. For HRV, the data strongly suggest that host susceptibility, reflected by parental atopy and allergic sensitization in the child, are critical factors in determining progression to asthma. In addition, wheezing with HRV infection in the third year of life has the greatest risk of asthma development. In contrast, infection with RSV is associated with greatest asthma risk when contracted in the first year of life, with little evidence of effect of parental atopy. The underlying mechanisms of progression to asthma for each virus are therefore likely to be different, and future studies need to focus on closely mimicking the known risk factors for each virus in order to identify species specific interventions to achieve primary or secondary prevention of asthma.

\section{Funding}

SS is funded by a Medical Research Council New Investigator Research Grant (number MR/ J010529/1).

\section{Conflict of interest statement}

The author has no conflict of interest to declare. 


\section{References}

Aberle, J., Aberle, S., Dworzak, M., Mandl, C., Rebhandl, W., Vollnhofer, G. et al. (1999) Reduced interferon-gamma expression in peripheral blood mononuclear cells of infants with severe respiratory syncytial virus disease. Am $\mathcal{F}$ Respir Crit Care Med 160: $1263-1268$.

Akinbami, L. and Schoendorf, K. (2002) Trends in childhood asthma: prevalence, health care utilization, and mortality. Pediatrics 110: 315-322.

Allander, T., Jartti, T., Gupta, S., Niesters, H., Lehtinen, P., Osterback, R. et al. (2007) Human bocavirus and acute wheezing in children. Clin Infect Dis 44: 904-910.

Andabaka, T., Nickerson, J., Rojas-Reyes, M., Rueda, J., Bacic, V. and Barsic, B. (2013) Monoclonal antibody for reducing the risk of respiratory syncytial virus infection in children. Cochrane Database Syst Rev 4: CD006602.

Bacharier, L., Cohen, R., Schweiger, T., Yin-Declue, H., Christie, C., Zheng, J. et al. (2012) Determinants of asthma after severe respiratory syncytial virus bronchiolitis. F Allergy Clin Immunol 130: 91-100.

Bisgaard, H., Hermansen, M., Bonnelykke, K., Stokholm, J., Baty, F., Skytt, N. et al. (2010) Association of bacteria and viruses with wheezy episodes in young children: prospective birth cohort study. BMF 341: c4978.

Bisgaard, H., Hermansen, M., Loland, L., Halkjaer, L. and Buchvald, F. (2006) Intermittent inhaled corticosteroids in infants with episodic wheezing. $N$ Engl $\mathcal{F}$ Med 354: 1998-2005.

Bousquet, J., Bieber, T., Fokkens, W., Kowalski, M., Humbert, M., Niggemann, B. et al. (2008) Important questions in allergy: novel research areas. Allergy 63: $143-147$.

Calvo, C., Garcia-Garcia, M., Blanco, C., Pozo, F., Flecha, I. and Perez-Brena, P. (2007) Role of rhinovirus in hospitalized infants with respiratory tract infections in Spain. Pediatr Infect Dis f 26: 904-908.

Camargo Jr, C., Ingham, T., Wickens, K., Thadhani, R., Silvers, K., Epton, M. et al. (2011) Cord-blood 25hydroxyvitamin D levels and risk of respiratory infection, wheezing, and asthma. Pediatrics

127: e180-e187.

Carroll, K., Gebretsadik, T., Minton, P., Woodward, K., Liu, Z., Miller, E. et al. (2012) Influence of maternal asthma on the cause and severity of infant acute respiratory tract infections. F Allergy Clin Immunol 129: 1236-1242.

Carroll, K., Wu, P., Gebretsadik, T., Griffin, M., Dupont, W., Mitchel, E. et al. (2009) The severitydependent relationship of infant bronchiolitis on the risk and morbidity of early childhood asthma. F Allergy Clin Immunol 123: 1055-1061.

Chi, A., Wildfire, J., McLoughlin, R., Wood, R., Bloomberg, G., Kattan, M. et al. (2011) Umbilical cord plasma 25-hydroxyvitamin D concentration and immune function at birth: the Urban Environment and Childhood Asthma study. Clin Exp Allergy 41: 842-850.

Collins, S., Pike, K., Inskip, H., Godfrey, K., Roberts, G., Holloway, J.W. et al. (2013) Validation of novel wheeze phenotypes using longitudinal airway function and atopic sensitization data in the first 6 years of life: evidence from the Southampton Women's survey. Pediatr Pulmonol 48: 683-692.

Culley, F., Pollott, J. and Openshaw, P. (2002) Age at first viral infection determines the pattern of $\mathrm{T}$ cellmediated disease during reinfection in adulthood. f Exp Med 196: 1381-1386.

Dakhama, A., Park, J., Taube, C., Joetham, A., Balhorn, A., Miyahara, N. et al. (2005) The enhancement or prevention of airway hyperresponsiveness during reinfection with respiratory syncytial virus is critically dependent on the age at first infection and IL13 production. F Immunol 175: 1876-1883.

de Vrese, M., Winkler, P., Rautenberg, P., Harder, T., Noah, C., Laue, C. et al. (2006) Probiotic bacteria reduced duration and severity but not the incidence of common cold episodes in a double blind, randomized, controlled trial. Vaccine 24: 6670-6674.

Empey, K., Orend, J., Peebles Jr, R., Egana, L., Norris, K., Oury, T. et al. (2012) Stimulation of immature lung macrophages with intranasal interferon gamma in a novel neonatal mouse model of respiratory syncytial virus infection. PLoS One 7: e40499.

Escobar, G., Ragins, A., Li, S., Prager, L., Masaquel, A. and Kipnis, P. (2010) Recurrent wheezing in the third year of life among children born at 32 weeks' gestation or later: relationship to laboratory-confirmed, medically attended infection with respiratory syncytial virus during the first year of life. Arch Pediatr Adolesc Med 164: 915-922.

Fujitsuka, A., Tsukagoshi, H., Arakawa, M., GotoSugai, K., Ryo, A., Okayama, Y. et al. (2011) A molecular epidemiological study of respiratory viruses detected in Japanese children with acute wheezing illness. BMC Infect Dis 11: 168.

Fullmer, J., Khan, A., Elidemir, O., Chiappetta, C., Stark, J. and Colasurdo, G. (2005) Role of cysteinyl leukotrienes in airway inflammation and responsiveness following RSV infection in BALB/c mice. Pediatr Allergy Immunol 16: 593-601.

Garcia-Garcia, M., Calvo, C., Casas, I., Bracamonte, T., Rellan, A., Gozalo, F. et al. (2007) Human metapneumovirus bronchiolitis in infancy is an important risk factor for asthma at age 5. Pediatr Pulmonol 42: 458-464.

Gern, J., Rosenthal, L., Sorkness, R. and Lemanske Jr, R. (2005) Effects of viral respiratory infections on lung development and childhood asthma. F Allergy Clin Immunol 115: 668-674.

Guilbert, T., Morgan, W., Zeiger, R., Mauger, D., Boehmer, S., Szefler, S. et al. (2006) Long-term 
inhaled corticosteroids in preschool children at high risk for asthma. N Engl f Med 354: 1985-1997.

Han, J., Jia, Y., Takeda, K., Shiraishi, Y., Okamoto, M., Dakhama, A. et al. (2010) Montelukast during primary infection prevents airway hyperresponsiveness and inflammation after reinfection with respiratory syncytial virus. Am $\mathcal{F}$ Respir Crit Care Med 182: 455-463.

Han, J., Takeda, K. and Gelfand, E. (2011) The role of RSV infection in asthma initiation and progression: findings in a mouse model. Pulm Med 2011: 748038.

Henderson, J., Granell, R., Heron, J., Sherriff, A., Simpson, A., Woodcock, A. et al. (2008) Associations of wheezing phenotypes in the first 6 years of life with atopy, lung function and airway responsiveness in midchildhood. Thorax 63: 974-980.

Henderson, J., Hilliard, T., Sherriff, A., Stalker, D., Al, S. and Thomas, H. (2005) Hospitalization for RSV bronchiolitis before 12 months of age and subsequent asthma, atopy and wheeze: a longitudinal birth cohort study. Pediatr Allergy Immunol 16: 386-392.

Jackson, D., Evans, M., Gangnon, R., Tisler, C., Pappas, T., Lee, W. et al. (2012) Evidence for a causal relationship between allergic sensitization and rhinovirus wheezing in early life. Am $\mathcal{F}$ Respir Crit Care Med 185: 281-285.

Jackson, D., Gangnon, R., Evans, M., Roberg, K., Anderson, E., Pappas, T. et al. (2008) Wheezing rhinovirus illnesses in early life predict asthma development in high-risk children. Am f Respir Crit Care Med 178: 667-672.

Jartti, T. and Gern, J. (2011) Rhinovirus-associated wheeze during infancy and asthma development. Curr Respir Med Rev 7: 160-166.

Jartti, T. and Korppi, M. (2011) Rhinovirus-induced bronchiolitis and asthma development. Pediatr Allergy Immunol 22: 350-355.

Jartti, T., Lee, W., Pappas, T., Evans, M., Lemanske Jr, R. and Gern, J. (2008) Serial viral infections in infants with recurrent respiratory illnesses. Eur Respir $\mathcal{F}$ 32: 314-320.

Jartti, T., Lehtinen, P., Vuorinen, T., Osterback, R., van den Hoogen, B., Osterhaus, A. et al. (2004) Respiratory picornaviruses and respiratory syncytial virus as causative agents of acute expiratory wheezing in children. Emerg Infect Dis 10: 1095-1101.

Jartti, T., Lehtinen, P., Vuorinen, T. and Ruuskanen, O. (2009) Bronchiolitis: age and previous wheezing episodes are linked to viral etiology and atopic characteristics. Pediatr Infect Dis f 28: 311-317.

Johnston, S., Pattemore, P., Sanderson, G., Smith, S., Lampe, F., Josephs, L. et al. (1995) Community study of role of viral infections in exacerbations of asthma in 9-11 year old children. BMF 310: 1225-1229.

Koponen, P., Helminen, M., Paassilta, M., Luukkaala, T. and Korppi, M. (2012) Preschool asthma after bronchiolitis in infancy. Eur Respir f 39: 76-80.
Korppi, M., Kuikka, L., Reijonen, T., Remes, K., Juntunen-Backman, K. and Launiala, K. (1994) Bronchial asthma and hyperreactivity after early childhood bronchiolitis or pneumonia. An 8-year follow-up study. Arch Pediatr Adolesc Med 148: 1079-1084.

Korppi, M., Piippo-Savolainen, E., Korhonen, K. and Remes, S. (2004) Respiratory morbidity 20 years after RSV infection in infancy. Pediatr Pulmonol

38: $155-160$.

Kotaniemi-Syrjanen, A., Laatikainen, A., Waris, M., Reijonen, T., Vainionpaa, R. and Korppi, M. (2005) Respiratory syncytial virus infection in children hospitalized for wheezing: virus-specific studies from infancy to preschool years. Acta Paediatr 94: 159-165.

Kotaniemi-Syrjanen, A., Reijonen, T., Korhonen, K. and Korppi, M. (2002) Wheezing requiring hospitalization in early childhood: predictive factors for asthma in a six-year follow-up. Pediatr Allergy Immunol 13: $418-425$

Kotaniemi-Syrjanen, A., Vainionpaa, R., Reijonen, T., Waris, M., Korhonen, K. and Korppi, M. (2003) Rhinovirus-induced wheezing in infancy - the first sign of childhood asthma? F Allergy Clin Immunol 111: 66-71.

Krishnamoorthy, N., Khare, A., Oriss, T., Raundhal, M., Morse, C., Yarlagadda, M. et al. (2012) Early infection with respiratory syncytial virus impairs regulatory $\mathrm{T}$ cell function and increases susceptibility to allergic asthma. Nat Med 18: 1525-1530.

Kristjansson, S., Bjarnarson, S., Wennergren, G., Palsdottir, A., Arnadottir, T., Haraldsson, A. et al. (2005) Respiratory syncytial virus and other respiratory viruses during the first 3 months of life promote a local TH2-like response. $\mathcal{F}$ Allergy Clin Immunol 116: 805-811.

Kusel, M., de Klerk, N., Kebadze, T., Vohma, V., Holt, P., Johnston, S. et al. (2007) Early-life respiratory viral infections, atopic sensitization, and risk of subsequent development of persistent asthma. F Allergy Clin Immunol 119: 1105-1110.

Lemanske Jr, R., Jackson, D., Gangnon, R., Evans, M., Li, Z., Shult, P. et al. (2005) Rhinovirus illnesses during infancy predict subsequent childhood wheezing. F Allergy Clin Immunol 116: 571-577.

Lowe, L., Murray, C., Custovic, A., Simpson, B., Kissen, P. and Woodcock, A. (2002) Specific airway resistance in 3-year-old children: a prospective cohort study. Lancet 359: 1904-1908.

Lowe, L., Simpson, A., Woodcock, A., Morris, J., Murray, C. and Custovic, A. (2005) Wheeze phenotypes and lung function in preschool children. $A m \mathcal{F}$ Respir Crit Care Med 171: 231-237.

Macaubas, C., de Klerk, N., Holt, B., Wee, C., Kendall, G., Firth, M. et al. (2003) Association between antenatal cytokine production and the development of atopy and asthma at age 6 years. Lancet 362: 1192-1197. 
Majak, P., Olszowiec-Chlebna, M., Smejda, K. and Stelmach, I. (2011) Vitamin D supplementation in children may prevent asthma exacerbation triggered by acute respiratory infection. $\mathcal{F}$ Allergy Clin Immunol 127: 1294-1296.

Martinez, F., Stern, D., Wright, A., Taussig, L. and Halonen, M. (1998) Differential immune responses to acute lower respiratory illness in early life and subsequent development of persistent wheezing and asthma. f Allergy Clin Immunol 102: 915-920.

Martinez, F., Wright, A., Taussig, L., Holberg, C., Halonen, M. and Morgan, W. (1995) Asthma and wheezing in the first six years of life. The Group Health Medical Associates. $N$ Engl f Med 332: 133-138.

Matricardi, P., Illi, S., Gruber, C., Keil, T., Nickel, R., Wahn, U. et al. (2008) Wheezing in childhood: incidence, longitudinal patterns and factors predicting persistence. Eur Respir f 32: 585-592.

O'Reilly, R., Ullmann, N., Irving, S., Bossley, C., Sonnappa, S., Zhu, J. et al. (2013) Increased airway smooth muscle in preschool wheezers who have asthma at school age. $\mathcal{F}$ Allergy Clin Immunol 131: 1024-1032.

Ochola, R., Sande, C., Fegan, G., Scott, P., Medley, G., Cane, P. et al. (2009) The level and duration of RSV-specific maternal IgG in infants in Kilifi Kenya. PLoS One 4: e8088.

Papadopoulos, N., Bates, P., Bardin, P., Papi, A., Leir, S., Fraenkel, D. et al. (2000) Rhinoviruses infect the lower airways. F Infect Dis 181: 1875-1884.

Poorisrisak, P., Halkjaer, L., Thomsen, S., Stensballe, L., Kyvik, K., Skytthe, A. et al. (2010) Causal direction between respiratory syncytial virus bronchiolitis and asthma studied in monozygotic twins. Chest 138: $338-344$.

Rakes, G., Arruda, E., Ingram, J., Hoover, G., Zambrano, J., Hayden, F. et al. (1999) Rhinovirus and respiratory syncytial virus in wheezing children requiring emergency care. $\operatorname{IgE}$ and eosinophil analyses. Am $\mathcal{F}$ Respir Crit Care Med 159: 785-790.

Razi, C., Harmanci, K., Abaci, A., Ozdemir, O., Hizli, S., Renda, R. et al. (2010) The immunostimulant OM$85 \mathrm{BV}$ prevents wheezing attacks in preschool children. f Allergy Clin Immunol 126: 763-769.

Renzi, P., Turgeon, J., Marcotte, J., Drblik, S., Berube, D., Gagnon, M. et al. (1999) Reduced interferon-gamma production in infants with bronchiolitis and asthma. Am $\mathcal{F}$ Respir Crit Care Med 159: $1417-1422$.

Ruotsalainen, M., Hyvarinen, M., Piippo-Savolainen, E. and Korppi, M. (2013) Adolescent asthma after rhinovirus and respiratory syncytial virus bronchiolitis. Pediatr Pulmonol 48: 633-639.

Saglani, S., Malmstrom, K., Pelkonen, A., Malmberg, L., Lindahl, H., Kajosaari, M. et al. (2005) Airway remodeling and inflammation in symptomatic infants with reversible airflow obstruction. Am $\mathcal{F}$ Respir Crit Care Med 171: 722-727.

Saglani, S., Payne, D., Zhu, J., Wang, Z., Nicholson, A., Bush, A. et al. (2007) Early detection of airway wall remodeling and eosinophilic inflammation in preschool wheezers. Am $\mathcal{F}$ Respir Crit Care Med 176: 858-864.

Savenije, O., Granell, R., Caudri, D., Koppelman, G., Smit, H., Wijga, A. et al. (2011) Comparison of childhood wheezing phenotypes in 2 birth cohorts: ALSPAC and PIAMA. $\mathcal{F}$ Allergy Clin Immunol 127: 1505-1512.

Schneider, D., Hong, J., Popova, A., Bowman, E., Linn, M., McLean, A. et al. (2012) Neonatal rhinovirus infection induces mucous metaplasia and airways hyperresponsiveness. F Immunol 188: 2894-2904.

Sherrill, D., Guerra, S., Wright, A., Morgan, W. and Martinez, F. (2011) Relation of early childhood growth and wheezing phenotypes to adult lung function. Pediatr Pulmonol 46: 956-963.

Sigurs, N., Aljassim, F., Kjellman, B., Robinson, P., Sigurbergsson, F., Bjarnason, R. et al. (2010) Asthma and allergy patterns over 18 years after severe RSV bronchiolitis in the first year of life. Thorax 65: 1045-1052.

Sigurs, N., Bjarnason, R., Sigurbergsson, F. and Kjellman, B. (2000) Respiratory syncytial virus bronchiolitis in infancy is an important risk factor for asthma and allergy at age 7. Am $\mathcal{F}$ Respir Crit Care Med 161: 1501-1507.

Stein, R., Sherrill, D., Morgan, W., Holberg, C., Halonen, M., Taussig, L. et al. (1999) Respiratory syncytial virus in early life and risk of wheeze and allergy by age 13 years. Lancet 354: 541-545.

Stensballe, L., Ravn, H., Kristensen, K., Meakins, T., Aaby, P. and Simoes, E. (2009a) Seasonal variation of maternally derived respiratory syncytial virus antibodies and association with infant hospitalizations for respiratory syncytial virus. F Pediatr 154: 296-298.

Stensballe, L., Simonsen, J., Thomsen, S., Larsen, A., Lysdal, S., Aaby, P. et al. (2009b) The causal direction in the association between respiratory syncytial virus hospitalization and asthma. F Allergy Clin Immunol 123: $131-137$.

Stephens, R., Randolph, D., Huang, G., Holtzman, M. and Chaplin, D. (2002) Antigen-nonspecific recruitment of Th2 cells to the lung as a mechanism for viral infection-induced allergic asthma. F Immunol 169: 5458-5467.

Stern, D., Morgan, W., Halonen, M., Wright, A. and Martinez, F. (2008) Wheezing and bronchial hyper-responsiveness in early childhood as predictors of newly diagnosed asthma in early adulthood: a longitudinal birth-cohort study. Lancet 372: 1058-1064.

Stokes, K., Chi, M., Sakamoto, K., Newcomb, D., Currier, M., Huckabee, M. et al. (2011) Differential 
Visit SAGE journals online http://tai.sagepub.com

(SSAGEJOURNALS pathogenesis of respiratory syncytial virus clinical isolates in BALB/c mice. F Virol 85: 5782-5793.

Taussig, L., Wright, A., Holberg, C., Halonen, M., Morgan, W. and Martinez, F. (2003) Tucson Children's Respiratory Study: 1980 to present. f Allergy Clin Immunol 111: 661-675.

Thomsen, S., van der Sluis, S., Stensballe, L., Posthuma, D., Skytthe, A., Kyvik, K. et al. (2009) Exploring the association between severe respiratory syncytial virus infection and asthma: a registry-based twin study. Am $\mathcal{F}$ Respir Crit Care Med 179: 1091-1097.

Valkonen, H., Waris, M., Ruohola, A., Ruuskanen, O. and Heikkinen, T. (2009) Recurrent wheezing after respiratory syncytial virus or non-respiratory syncytial virus bronchiolitis in infancy: a 3-year follow-up. Allergy 64: 1359-1365.

Wright, A., Taussig, L., Ray, C., Harrison, H. and Holberg, C. (1989) The Tucson Children's

Respiratory Study. II. Lower respiratory tract illness in the first year of life. Am F Epidemiol 129: 1232-1246.

Wu, P., Dupont, W., Griffin, M., Carroll, K., Mitchel, E., Gebretsadik, T. et al. (2008) Evidence of a causal role of winter virus infection during infancy in early childhood asthma. Am $\mathcal{F}$ Respir Crit Care Med 178: 1123-1129.

Wu, P. and Hartert, T. (2011) Evidence for a causal relationship between respiratory syncytial virus infection and asthma. Expert Rev Anti Infect Ther 9: $731-745$. 